\title{
A Comparative Study of Consumption Propensity and Determinants of Purchasing According to Cultural Differences between Baby Boomers and Millennials: Application to Franchise Customers
}

\author{
Hyun-Sik Roh*, Sung-Ho Lee**, Sung-Hoon Kim*** \\ Received: March 1, 2020 Revised: March 0, 2020 Accepted: March 0, 2020.
}

\begin{abstract}
Purpose: The baby boomers and the millennials, who make up the largest share of the market, are showing the gap in their differentiated cultural styles. The purpose of this study is to study the consumption propensity and purchasing determinants of the baby boomers generation and the millennials generation, which have become a very important key pillar in shaping the market based on the cultural dimension model theory of $\mathrm{h}(=>\mathrm{H})$ opstead, and to identify the difference Research design, data, and methodology: In order to verify the research hypotheses, The data was collected from the baby boomers and the millennials using online questionnaires. The pre-test was conducted from October 10 to 12,2019 , and the main survey was conducted from October 15 to 25 . A total of 230 copies were recalled, and the final 219 copies were used for the final analysis. Results: The consumption propensity between the baby boomers and the millennials differed in resource saving purchase propensity and impulse buying propensity. The baby boomers showed higher resource saving purchase propensity than the millennials, while the millennials showed higher impulse buying propensity. There was a difference in the determinants to purchasing only in the evaluation factor. Results of gender differences by generation, baby boomers differed in their planned purchase propensity, and women were higher. The millennials generation differed in resource saving purchase propensity and awareness propensity for others, all higher in men. In determinants to purchasing, the baby boomers did not differ in gender, and the millennials did differ in product factors. A canonical correlations analysis of the relationship between the baby boomers and the millennials showed a significant relationship between consumption propensity and determinants to purchasing. Also, the baby boomer generation has the biggest link between impulse buying propensity and evaluation factor. The millennials generation showed the biggest link between resource saving purchase and product factors. Conclusions: This study compared consumption propensity and determinants to purchasing of baby boomers and millennials on the basis of Hopstead's cultural dimension model theory to identify differences between generations, presenting practical and theoretical implications for establishing a correct understanding and specific marketing strategy among generation.
\end{abstract}

Keywords: Consumption Propensity, Cultural Dimensions, Baby Boomers, Millennials, Franchise Customers

JEL Classification: M3, M31, M37

\section{1. 서론}

*First Author, Doctoral student, Graduate School of Business, Sejong University, CEO, T's LEADERS, Seoul, Korea.

Email: bizroh@gmail.com

${ }^{* *}$ Second Author, Doctoral student, Graduate School of Business, Sejong University, CEO, SuSpeech Leadership Center, Seoul, Korea. Email: suspeech@naver.com

${ }^{* * *}$ Corresponding Author, Doctoral student, Graduate School of Business, Sejong University, Email: 16121301@naver.com

(1) Copyright: Korean Distribution Science Association (KODISA)

This is an Open Access article distributed under the terms of the Creative Commons Attribution NonCommercial License (https:///reativecommons.org/licenses/by-nc/4.0/) which permits unrestricted no -
우리 사회는 다양한 세대가 혼재되어 있으며 베이비 부머 세대 (Baby boomer generation), 386 세대, $X$ 세대, 밀레니얼 세대(Millennial generation) 등 3 4개의 세대가 한 사회 혹은 조직, 가정 등을 구성하고 있다. 이러한 이유로, 각 조직이나 사회에서 세대 간에 언어표현, 행동양식, 사고방식에서 격차가 매우 심하게 벌어지는 현상을 보이고 있다Chung, 2019).

특히, 이러한 세대 중 베이비 부머 세대와 밀레니얼 세대는 인구통계적으로 큰 비중을 차지하며 두드러지게 차별화된 문화와 생활양식을 보여주고 있다. 베이비 부머 세대는 사회적 용어로 특정한 시기에 출산이 집중적으로 늘어 출생아 수가 급격하게 증가하는 상황을 
의미한다(KNPS, 2006). 출산율이 급증했던 1955 년부터 산아 제한 정책으로 둔화된 1963 년 사이에 태어난 이 세대는, 현재 711 만 명으로 총인구의 $13.9 \%$ 를 차지하는 큰 비중의 인구 집단이다KOSTAT, 2018). 밀레니얼 세대는 1980 년부터 2000 년 사이에 태어난 사람들로 Howe \& Strauss 가 1991 년에 출간한 저서 Generations: The History of America's Future 에서 용어가 처음 사용 되었다(Howe \& Strauss, 1992). 국내 밀레니얼 세대의 소비인구는 1445 만 명으로 추산되고, 전체의 $23 \%$ 정도를 차지하며, 50 60 대 베이비 부머를 앞지르고 있으며 2025 년에는 $50 \%$ 에 육박하는 소비의 중심 소비자가 될 전망이다Shin \& Lee, 2018).

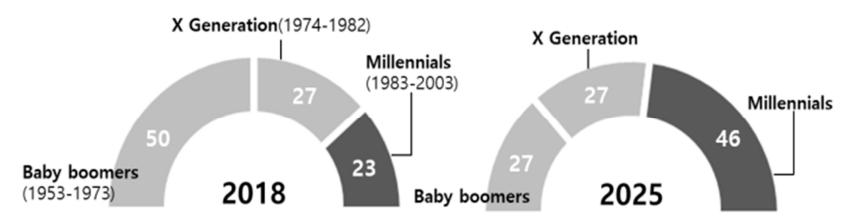

Figure 1: A Change in the Consumption Population Sources: Shin \& Lee, 2018.

이렇게 큰 비중을 차지하는 베이비 부머 세대와 밀레니얼 세대는 시장의 핵심 축과 흐름을 형성하고 있다. 중요 시장으로 자리 잡고 있는 밀레니얼 세대에 대한 최근 연구는 그들의 성향과 특성, 문화를 중심으로 한 연구KKim, 2019; Lee \& Lee, 2019; Jo \& Cho, 2019; Hong \& Kwon, 2019)들이 주로 이루어 졌으며, 베이비 부머 세대에 대한 최근 연구는 은퇴 및 노후 대비를 중심으로 한 연구들(Shin, 2019; Song \& Won, 2019; Yoon \& Park, 2019; Lee \& Park, 2019)이 주를 이루고 있다. 세대에 대해 개별적인 연구는 다양하게 진행되어 왔으나, 베이비 부머 세대와 밀레니얼 세대 간의 직접적이고 실증적인 비교연구는 이루어지지 않아 각 세대의 특성을 바탕으로 시장을 이해하고 올바른 마케팅 전략을 수립하는데 필요한 연구는 미흡한 실정이다.

한편, 세대 간의 연구는 프랜차이즈가 도입된 1979 년 이후 매년 급성장(Park, Lee \& Choi, 2015)하고 있는 우리나라의 프랜차이즈 산업에서도 올바른 프랜차이즈 마케팅 전략을 수립하기 위하여 절대적으로 필요하나 이에 대한 연구가 거의 이루어지지 않았다. 산업자원통상부(MOTIE)에 따르면, 2018 년 기준 가맹본부 4,631 개, 브랜드 5,741 개, 가맹점 수 는 24.8만 개로 2005 년 대비 109.4\%(가맹본부 수 기준)의 성장(MOTIE, 2005)을 보이는 것으로 집계 되어지고 있으며, 다양한 유형의 프랜차이즈(Lee \& Park, 2010)는 업종별로는 외식업 75\%, 서비스업 $19 \%$, 도소매업 $6 \%$ 로 다양한 세대를 주 소비자로 상대하는 외식업과 서비스업이 94\%를 차지하고 있다(MOTE, 2019). 이와 같이 프랜차이즈 산업의 외적 성장과 함께 다양한 주제에 대하여 많은 학자들이 연구를 진행하였으나, 프랜차이즈 산업 분야와 외식, 서비스 분야에서 밀레니얼 세대Lee et al, 2018; Varindra, 2018; Lee, Dagvadori, \& Kim, 2019)와 베이비 부머 세대(Kim, Kim, \& Song, 2013; Choi, 2016의
개별적인 연구는 매우 적으며, 세대 간의 직접적인 비교 연구는 찾아보기 어렵다.

따라서 본 연구는 개인의 심리적 상황을 설명하는 Hofstede 의 문화차원 모형이론(Hofstede, Hofstede, \& Minkov, 2005)을 이용하여 베이비 부머 세대와 밀레니얼 세대의 소비성향과 구매결정요인을 각 각 알아보고 그 차이를 연구하고자 한다. 이러한 본 연구의 시도는 다양한 세대의 소비자 가치를 파악하고, 그들의 소비성향이 무엇인가를 파악함으로써 프랜차이즈 마케터들이 표적고객의 설정 및 그에 맞는 올바른 마케팅전략을 어떻게 수립할 것인가에 대한 방향을 제시할 수 있을 것이다.

본 연구의 연구과제는 다음과 같다.

첫째, 베이비 부머와 밀레니얼 세대 각각의 소비성향과 구매결정 요인을 알아보고 세대 간의 차이는 발생하는가?

둘째, 베이비 부머와 밀레니얼 세대 내 성별에 따른 소비성향과 구매결정요인에 대한 차이는 발생하는가?

셋째, 베이비 부머와 밀레니얼 각각의 세대에서 소비성향과 구매결정요인 간에는 어떠한 상관관계가 있는가? 또한 그러한 상관관계에는 세대 간 차이가 있는가?

\section{2. 이론적 고찰}

\section{1. 홉스테드의 문화차원 모형이론}

문화란 집단이나 사람의 범주를 구분시키고 사람간의 공유를 전제로 한다는 점에서의 집단현상이며, 집단 간의 심리적 경계 기능과 감정사고잠재적 행위의 생활양식이라는 점에서 정신적 소프트웨어(software of the mind) 또는 집단적 정신 프로그래밍 (collective programming of the mind)이다(-Hofstede, Hoftede, \& Minkov, 2005). Hofstede(1980)는 전 세계 50 여개 국에 분포되어 있는 다국적 기업인 $\mathrm{IBM}$ 근무자들을 대상으로 연구하여 권력거리(Power distance), 개인주의(Individualism)-집단주의(Collectivism), 남성(Masalinity)-여성성 (Feminity), 불확실성 회피(Uncertainty avoidance) 등 4 개 차원으로 문화 차원을 설명하였다(Hofstede, 1993). 권력거리는 사회의 권력과 부가 불평등하게 배분되어 있거나 편중되어 있을 때 이를 속한 사회에서 수용하는 정도를 의미한다. 개인주의-집단주의는 개인과 집단이 정체성과 역할을 구분하는 것을 기초로 국가 단체, 가족 그리고 공동체에 대한 개인적인 자유의 요구 정도와 의무의 수용 정도를 의미한다. 남성성-여성성 차원은 거의 모든 사회에서 남성의 역할과 연관된 '강인함의 가치(tough values'가 여성의 역할과 연관된 '부드러움의 가치(tender values)'를 압도하는 정도를 나타내는 것으로 
사회적 성(gender)의 역할을 기초로 남성성과 여성성을 정의한다 (Hofstede, 1993). 마지막으로, 불확실성 회피는 불명확한 비구조적 상황 대비 명확한 구조적 상황에 대한 선호 정도를 나타내는 것으로 한 문화의 구성원들이 불확실한 상황이나 미지의 상황으로 인해 위협을 느끼는 정도로 설명된다. 이러한 문화차이에서 가장 내면적인 가치수준은 $50 \%$ 이상이 어렸을 때(0 10 세쯤) 부모로부터 습득되어 무의식 속에 저장되어 있다(Hofstede et al, 1990). 본 연구는 이러한 홉스테드의 문화차원 모형이론을 바탕으로 세대 간의 문화 차이를 비교해 보고자 한다.

\section{2. 베이비 부머와 밀레니얼 세대의 특성}

세대 정체성은 정치, 경제, 사회적 사건이나 현상을 원인으로 하여, 한 세대와 다른 세대 사이의 문화적 특성의 차이로 설명할 수 있다(Kupperschmidt, 2000). 세대는 성년기에 이르는 동안 동일한 역사적, 사회 문화적 맥락에서 동일한 경험을 함으로써 일종의 연대적 정향이나 공동의 태도가 형성된 연령 집단으로 정의될 수 있다(Ryu. 2019).

우리 나라의 베이비 부머 세대의 시작은 한국전쟁 이후 출생한 세대로 일반적으로 정의 내려진 다른 국가와는 약 10 년 정도의 차이가 난다. 대체로 1960 년대 대가족 내에서 사회화 과정을 겪으며 성장하였고, 1970 년대 핵가족으로의 가족구조 변화를 경험한 세대로 보수와 진보, 혹은 전통과 혁신이라는 이중 잣대를 가진 것으로도 보인다(Park, 2013). 이 세대는 한국 경제의 고도성장을 이끈 중추세대로서 한국의 가난과 근대화를 동시에 경험하며 본격적인 체계화 교육을 받고 치열한 입시제도 속에 부지런하고 성취욕이 강한 세대로 자라나게 되었다. 또한, IMF, 세계 금융위기 등 경제적 어려움 겪은 세대이기도 하다(MOEL, 2017).

반면에, 밀레니얼 세대는 디지털 매체 환경을 기반으로 한 생활환경을 가지고 있다. 밀레니얼 세대가 기성 세대와 가장 뚜렷하게 구분되는 특성으로 컴퓨터 문화가 일반화된 첫 세대로 청소년 때부터 모바일, 소셜 네트워크 서비스 등 다양한 디지털 매체와 인터넷의 보급 등을 경험한 세대이다(Park, 2010). 이러한 밀레니얼 세대는 다음과 같은 특징을 보인다. 첫째, 정보화 세대로 디지털 정보탐색 능력이 뛰어나고 온라인으로 소통하는 것에 익숙한 세대이다(Tapacross, 2017). 둘째, 부모로부터 받은 경제적 풍요와 지지로 성취감과 자존감이 높다(Ye \& Chin, 2009). 셋째, 자율화의 시대적 배경으로 자신들이 추구하고자 하는 다양한 가치를 중요시한다(Park, 2010; Smola \& Sutton, 2002).

이와 같이 세대 간에는 성년기에 이르는 동안 서로 다른 사회 문화적, 역사적 맥락에서 다른 경험을 함으로써 연대적 정향이나 공동의 태도가 다르게 형성되었다. 그러므로 본 연구에서는 다르게 형성된 베이비
부머와 밀레니얼 세대 간의 특징 중 소비성향과 구매의결정요인의 차이를 알아보고자 한다.

\section{3. 소비성향}

소비성향은 소비자가 물건을 구매하는 과정에서 비교적 일관되게 보여 지는 심리적 경향으로 개별 소비자의 특성을 결정짓는 요인(Kim \& Rhee, 2007)으로 다차원적인 성격을 가진 소비에 대한 흥미, 의견, 활동을 포함하는 소비영역에서의 구체적인 생활양식 (Darden \& Howell, 1987)이다. 소비성향은 제품을 구매하고 사용하며, 그것에 대해 어떻게 생각하고 느낌이 어떠한지를 포함하는 개념으로 정의하면서, 소비의 구조적 특성을 기초로 하여 인간 상호관계 측면에서의 소비성향의 체계를 설명하였다(Holt, 1995). 이러한 소비성향을 구성하는 하위영역은 다양한 차원으로 학자들에 의해 연구되어지고 분류되어왔다. Woo \& Lee(2008)는 권위추구형, 휴식추구형, 실속추구형, 체험추구형, Kim(1996)은 공익성, 합립성, 충동성, 효율성, 향유성, 사회성, 그리고 Lee \& Lee(2016)는 계획구매, 자원절약, 과시소비, 충동구매, 타인의식 성향 등으로 분류하였다. 한편, 다양한 차원으로 분류된 소비성향의 대표적인 개념을 모두 포함하고 있는 Kang \& Sin(2006)의 소비성향 하위 영역을 본 연구에서는 사용하였으며 자원절약성향, 타인의식성향, 계획구매 성향, 충동구매 성향으로 구분하였다.

자원절약성향은 값싼 물건이라도 소중히 아끼고, 물건을 살 때는 언제나 나의 형편과 처지에 적절한 가를 생각해 보며, 쓰던 물건을 오래 사용하는 등으로 정의된다. 타인의식성향은 편리한 물품을 자주 구입하며 새롭게 눈에 띄는 것이 있으면 즉시 사는 것을 말한다. 계획구매성향은 물건을 살 때는 미리 계획을 세워 여러 상점을 살펴보고 비교한 후 사고 구입 목록대로 구입하는 등으로 정의된다. 그리고 충동구매성향은 언제나 다른 사람의 평가를 의식하면서 제품을 구입하며 편리한 물품을 자주 구입하며 새롭게 눈에 띄는 것이 있으면 즉시 사는 등으로 정의된다.

\section{3. 구매결정요인}

구매결정요인은 경제적 재화와 서비스를 획득하고 사용하는데 직접적으로 연관된 개인의 행동 및 행동의 결정에 선행하는 제반 의사결정과정(Engel \& Blackwell, 1986)으로 소비자의 정신적, 인지적 성향은 구매결정에 지속적인 영향을 미친다(Sproles \& Kendall, 1986).

본 연구에서는 Kang \& Sin(2006)의 연구를 바탕으로 구매결정 요인을 제품 요인, 브랜드 요인, 평가 요인으로 분류한다. 제품요인 은 제품의 기능과 품질, 용기 및 포장, 가격, 사용의 편리성과 디자인, 브랜드 
요인은 브랜드 제조회사 및 이미지, 제품의 신뢰도와 명성, 원산지, 그리고 평가 요인은 명성과 이미지, 주변인의 평가를 말한다.

\section{4. 소비성향과 구매결정요인과의 관계}

$\mathrm{Ha}(2019)$ 의 헬스\&뷰티 스토어의 소비성향이 구매결정요인에 미치는 영향에서 계획구매 소비성향은 제품 요인에 따라 구매를 결정하는 경우가 가장 높았고, 유행추구 소비성향일수록 점포요인에 따라 구매를 결정하는 성향이 높게 나타났다.

Kang \& $\operatorname{Sin}(2006)$ 의 소비성향에 따른 화장품 소비자의 구매결정 요인 연구에서 소비성향에 따른 구매결정요인에 가장 큰 변별력을 보인 집단은 유행추구성향, 과시소비성향이었다. 국산 또는 수입 화장품 사용 구매결정요인에서는 제품의 품질과 기능이 가장 중요한 것으로 나타났으며, 전반적으로 화장품 구매 시 수입화장품 사용 집단이 국산화장품 사용 집단에 비해 제품의 가격을 제외한 모든 구매결정요인에서 더 신중한 자세를 지니고 있음을 보였다. 이렇듯 집단에 따라 구매결정요인은 다르게 나타났다.

한편, Kim \& Lee(2019)는 여대생의 화장품 소비성향이 구매 결정요인에 미치는 연구를 실시하여, 화장품 소비성향 중 타인의식 성향, 계획구매 성향, 충동구매 성향이 화장품 구매 결정요인에 긍정적인 영향을 미치는 것을 발견하였다.

위의 선행연구와 같이 소비성향과 구매결정요인 간에는 관계가 있음을 알 수 있다.

\section{3. 연구설계}

\section{1. 연구문제}

본 연구에서는 홉스테드의 문화차원 모형이론과 베이비 부머와 밀레니얼 세대의 특징, 소비성향, 구매결정요인의 개념적 정의와 관계에 대한 이론적 고찰을 바탕으로 베이비 부머와 밀레니얼 세대 간 소비성향과 구매결정요인의 차이와 관계를 알아보기 위하여 다음과 같은 연구문제를 설정하였다.

Hypothesis 1: 베이비 부머와 밀레니얼 세대 간 소비성향에 대한 지각된 차이가 있을 것이다.

Hypothesis 2: 베이비 부머와 밀레니얼 세대 간 구매결정요인에 대한 지각된 차이가 있을 것이다.
Hypothesis 3: 베이비 부머와 밀레니얼 세대 내에 성별에 따른 소비성향에 대한 지각된 차이가 있을 것이다.

Hypothesis 4: 베이비 부머와 밀레니얼 세대 내에 성별에 따른 구매결정요인에 대한 지각된 차이가 있을 것이다.

Hypothesis 5: 베이비 부머 세대의 소비성향과 구매결정요인 간에는 유의한 상관관계가 있을 것이다.

Hypothesis 6: 밀레니얼 세대의 소비성향과 구매결정요인 간에는 유의한 상관관계가 있을 것이다.

Hypothesis 7: 베이비 부머 세대와 밀레니얼 세대 간 소비성향과 구매결정요인에 유의한 상관관계는 차이가 있을 것이다.

\section{2. 변수의 조작적 정의와 측정}

본 연구는 베이비 부머 세대와 밀레니얼 세대 간에 소비성향과 구매결정요인에 유의한 차이가 있는지 검증하고자 선행연구를 고찰하여 이를 기반으로 설문지를 구성하였다.

먼저 표본의 인구 통계적 특성은 명목척도와 서열척도로 측정 가능한 세대, 연령, 성별, 학력, 직업, 소득으로 구성하여 측정되었다.

소비성향은 자원절약성향, 타인의식성향, 계획구매성향, 충동구매 성향 차원으로 구성되며(Kim, 1996; Park \& Kim, 2004; Kang \& Sin, 2006), 7 점 리커트 척도 1 점 $=$ 전형 동의하지 않는다, 7 점 $=$ 전적으로 동의한다)로 측정되었다. 구매결정요인은 Kang \& $\operatorname{Sin}(2006)$ 의 선행연구를 토대로 제품 요인, 브랜드 요인, 그리고 평가 요인의 세 개 하위차원으로 구성되며, 7 점 리커트 척도 $(1$ 점 $=$ 전형 동의하지 않는다, 7 점 $=$ 전적으로 동의한다)로 측정되었다.

\section{3. 표본설계 및 분석방법}

선행연구와 이론적 고찰을 통해 홉스테드의 문화차원 모형이론이 가진 특징을 살펴보고, 이를 바탕으로 세대(베이비 부머 세대, 밀레니얼 세대)와 성별(남성, 여성)에 따른 소비성향과 구매결정 요인에 차이가 있는지 검증하기에 앞서 2019 년 10 월 10 일 부터 2019 년 10 월 12 일까지 베이비 부머 세대 20 명과 밀레니얼 세대 20 명을 대상으로 예비조사가 진행되었다. 응답자의 의견을 반영하고 내용 타당성이 저해되는 문항을 파악하여 본 조사를 위한 설문지가 최종 보완되었다. 예비 조사 결과, 측정 변수의 타당도와 신뢰도는 본 조사를 진행하는데 큰 무리가 없는 것으로 확인되어 2019 년 10 월 15 일 부터 2019 년 10 월 25 일까지 본 조사가 실시되었다. 본 조사는 편의표본추출법을 사용하여 실시되었으며, 온라인 구글 설문 폼(Google Form)을 통해 설문지의 배포 및 회수작업이 진행되었다. 총 230 부가 회수되었으나, 불성실한 응답과 
분석에 적합하지 않다고 판단되는 11 부를 제외한, 최종 219 부가 최종분석에 활용되었다.

\section{4. 실증분석}

\section{1. 응답자의 인구통계학적 특성}

응답자의 인구 통계적 특성은 Table: 1 과 같다. 전체 표본 219 명 중 베이비 부머와 밀레니얼 세대는 각각 $52.5 \%, 475 \%$ 로 베이비 부머 세대가 약간 많은 것으로 나타났다. 전체적인 성별은 여성(524\%)이 남성(47.6\%)에 비하여 약간 많은 것으로 나타났다. 세대별 성별은 베이비 부머 세대에서는 여성(661\%) 이 남성(33.9\%) 보다 많으며, 밀레니얼 세대에서는 남성(57.7\%)이 여성(423\%)에 비해 약간 많은 것으로 나타났다. 연령은 20 대(34.7\%)가 가장 많았으며, 학력은 대졸이상 $(36.5 \%)$, 고졸 $(4.7 \%)$, 전문대졸(17.4\%), 대학원 이상(114\%) 순으로 나타났다.

Table 1: Demographic Profile of the Respondents ( $\mathrm{n}=219)$

\begin{tabular}{|c|c|c|c|c|c|c|c|}
\hline \multirow{3}{*}{\multicolumn{2}{|c|}{ Demographic variables }} & \multirow{2}{*}{\multicolumn{2}{|c|}{ Total }} & \multicolumn{4}{|c|}{ Generation } \\
\hline & & & & \multicolumn{2}{|c|}{ Baby Boomers } & \multicolumn{2}{|c|}{ Millennials } \\
\hline & & Frequency(n) & $\%$ & Frequency(n) & $\%$ & Frequency(n) & $\%$ \\
\hline \multirow{2}{*}{ Gender } & Male & 108 & 47.6 & 39 & 33.9 & 60 & 57.7 \\
\hline & Female & 119 & 52.4 & 79 & 66.1 & 44 & 42.3 \\
\hline \multirow{5}{*}{ Age } & $20 \mathrm{~s}$ & 76 & 34.7 & 0 & 0 & 76 & 73.1 \\
\hline & $30 \mathrm{~s}$ & 27 & 12.3 & 0 & 0 & 27 & 26.9 \\
\hline & $40 \mathrm{~s}$ & 49 & 22.4 & 49 & 42.6 & 0 & 0 \\
\hline & $50 \mathrm{~s}$ & 60 & 27.4 & 59 & 51.3 & 0 & 0 \\
\hline & $60 \mathrm{~s}$ & 7 & 3.2 & 7 & 6.1 & 0 & 0 \\
\hline \multirow{4}{*}{$\begin{array}{l}\text { Education } \\
\text { Level }\end{array}$} & High school & 76 & 34.7 & 37 & 32.3 & 39 & 37.5 \\
\hline & Two year college & 38 & 17.4 & 19 & 16.5 & 19 & 18.3 \\
\hline & University & 80 & 36.5 & 39 & 33.9 & 41 & 39.4 \\
\hline & Master Course & 25 & 11.4 & 20 & 17.4 & 5 & 4.8 \\
\hline \multirow{8}{*}{ Job } & Professionals & 45 & 20.5 & 25 & 21.7 & 20 & 19.2 \\
\hline & Public official & 9 & 4.1 & 7 & 6.1 & 2 & 1.9 \\
\hline & Salaryman & 37 & 16.9 & 18 & 15.7 & 19 & 18.3 \\
\hline & Self-employed & 19 & 8.7 & 15 & 13.0 & 4 & 3.8 \\
\hline & Service & 19 & 8.7 & 10 & 8.7 & 9 & 8.7 \\
\hline & Manufacture worker & 9 & 4.1 & 6 & 5.2 & 3 & 2.9 \\
\hline & Housewife & 19 & 8.7 & 18 & 15.7 & 1 & 1.0 \\
\hline & Others & 62 & 28.3 & 16 & 13.9 & 46 & 44.2 \\
\hline \multirow{4}{*}{$\begin{array}{l}\text { Income } \\
\text { (unit=won) }\end{array}$} & Under 2 million & 78 & 35.6 & 26 & 22.6 & 52 & 50.0 \\
\hline & $2 \sim<4$ million & 90 & 41.1 & 45 & 39.1 & 45 & 43.3 \\
\hline & $4 \sim<6$ million & 36 & 16.4 & 32 & 27.8 & 4 & 3.8 \\
\hline & Above 6 million & 15 & 6.8 & 12 & 10.4 & 3 & 2.9 \\
\hline \multicolumn{2}{|c|}{ Total } & 219 & 100.0 & 115 & 52.5 & 104 & 47.5 \\
\hline
\end{tabular}


응답자의 직업은 기타를 제외한 전문직이 $20.5 \%$ 로 가장 많고, 소득은 201-400 만원 미만의 구간이 전체의 $41.1 \%$ 차지해 가장 높은 비율을 보이는 것으로 나타났다.

\section{2. 측정도구의 타당성 및 신뢰성 분석}

연구에 사용된 변수들의 타당성과 신뢰성을 검증하기 위해서 탐색적 요인분석과 신뢰도 분석이 실시되었다. 탐색적 요인분석은 데이터에 포함된 정보의 손실을 최소화하여 축소하는 주성분 분석과 요인들 간의 독립성을 유지하는 직각회전방식으로 진행되었다.

표본의 적합도는 $\mathrm{KMO}($ Kaiser-Meyer-Olkin) 값과 Bartlett의 구형성 검정 결과로 나타난 유의도로 확인되었다. 연구에 사용된 변수들의 타당성과 신뢰성을 검증하기 위해서 탐색적 요인분석과 신뢰도 분석이 실시되었다. 탐색적 요인분석은 데이터에 포함된 정보의 손실을 최소화하여 축소하는 주성분 분석과 요인들 간의 독립성을 유지하는 직각회전 방식으로 진행되었다.

표본의 적합도는 $\mathrm{KMO}($ Kaiser-Meyer-Olkin) 값과 Bartlett의 구형성 검정 결과로 나타난 유의도로 확인되었다. 요인분석에서 고유 값 1 이상, 공통성 4 이상, 요인적재치 4 이상으로 도출된 요인이 차후 분석에 이용되었다.

\subsection{1 소비성향의 요인분석 및 신뢰도분석}

Table 2: Exploratory Factor Analysis and Reliability Analysis

\begin{tabular}{|c|c|c|c|c|c|}
\hline \multicolumn{2}{|r|}{ Factors and items } & $\begin{array}{l}\text { Factor } \\
\text { loading }\end{array}$ & $\begin{array}{l}\text { Eigen } \\
\text { values }\end{array}$ & $\begin{array}{c}\text { Explain } \\
\text { Variance(\%) }\end{array}$ & Cronbach $\alpha$ \\
\hline \multirow{11}{*}{$\begin{array}{l}\text { Consumption } \\
\text { propensity }\end{array}$} & Resource saving purchase propensity & & 3.191 & 18.772 & .746 \\
\hline & $\begin{array}{l}\text { I tend to try to use my old one for a long time rather than } \\
\text { buying new ones. }\end{array}$ & .794 & & & \\
\hline & I tend to buy only the products that I really need. & .787 & & & \\
\hline & They tend to Precious cherish, and use even cheap goods. & .676 & & & \\
\hline & $\begin{array}{l}\text { I always think about the propriety of my situation and } \\
\text { situation when I buy things. }\end{array}$ & .490 & & & \\
\hline & Awareness propensity for others & & 2.804 & 16.491 & .752 \\
\hline & $\begin{array}{l}\text { When I use a trendy or expensive product, I would be } \\
\text { happy if other people would recognize me. }\end{array}$ & .845 & & & \\
\hline & $\begin{array}{l}\text { I feel good when I talk to others about high-end products I } \\
\text { own. }\end{array}$ & .839 & & & \\
\hline & $\begin{array}{l}\text { When I buy something, I tend to be aware of other people's } \\
\text { evaluations. }\end{array}$ & .687 & & & \\
\hline & I look carefully at what people around me wear. & .518 & & & \\
\hline & Planned purchase propensity & & 2.484 & 14.613 & .759 \\
\hline
\end{tabular}

요인 분석 결과, 소비성향은 총 네 개의 요인으로 도출되었다. 총 분산 설명력은 $61.93 \%$ 이며, 요인별 설명력은 자원절약성향이 가장 높고 타인의식성향, 계획구매성향, 충동구매성향 순으로 나타났다. 각 요인별 고유 값(3.191 2.049)은 모두 1.0 이상이고, 표본의 적합도를 나타내는 $\mathrm{KMO}$ 값은 810 , Bartlett의 구형성 검정 결과는 유의한 것으로 나타나서 이 표본은 요인분석을 하기에 적절한 것으로 확인되었다. 신뢰도 계수 대한 신뢰도가 확보되었다(Hidden Grace, 2018). 소비성향에 대한 요인분석 및 신뢰도 분석 결과는 Table: 2 와 같다.

\subsection{2 구매결정요인 요인분석 및 신뢰도분석}

구매결정요인에 대한 요인 분석 결과, 구매결정요인은 예상한데로 3 개의 요인으로 도출되었다. 총 분산 설명력은 $61.830 \%$ 이며, 요인별 설명력은 제품요인이 가장 높고 브랜드 요인, 평가요인 순으로 나타났다. 각 요인별 고유 값(2.176 1.939)은 모두 10 이상이고, 표본의 적합도를 나타내는 $\mathrm{KMO}$ 값은 $801, \mathrm{Bartlett}$ 의 구형성 검정 결과는 확인되었다.

신뢰도 계수 Cronbach's $\alpha$ 는 모두 .6이상인 .715 .662 값을 보여 나타나 측정 항목에 대한 신뢰도가 확보되었다. 소비성향에 대한 요인분석 및 신뢰도분석 결과는 Table: 2 와 같다. Cronbach's $\alpha$ 는 모두 .6 이상인 .861 .752 수준으로 나타나 측정 항목에 유의한 것으로 나타나 이 표본은 요인분석을 하기에 적절한 것으로 


\begin{tabular}{|c|c|c|c|c|c|}
\hline & I tend to buy products using discount period of products. & .864 & & & \\
\hline & I find and buy the cheapest way to buy things. & .844 & & & \\
\hline & I tend to plan and buy anything in advance. & .506 & & & \\
\hline & $\begin{array}{l}\text { Before shopping, I tend to make a list of purchases and buy } \\
\text { them according to the list. }\end{array}$ & .490 & & & \\
\hline & Impulse buying propensity & & 2.049 & 12.054 & .861 \\
\hline & $\begin{array}{l}\text { When new and unique products come out, I tend to buy } \\
\text { them immediately. }\end{array}$ & .756 & & & \\
\hline & $\begin{array}{l}\text { Even unplanned products are often purchased if they are } \\
\text { liked. }\end{array}$ & .689 & & & \\
\hline & I tend to buy what I want regardless of other people's eyes. & .756 & & & \\
\hline & $\begin{array}{l}\text { I think living happily today is a happier life than saving } \\
\text { money for an opaque future. }\end{array}$ & .815 & & & \\
\hline & $\begin{array}{l}\text { I tend to buy expensive goods by all means when I want } \\
\text { them. }\end{array}$ & .712 & & & \\
\hline & \multicolumn{5}{|c|}{$\mathrm{KMO}=.810$, Bartlett $=1552.916(\mathrm{df}=136, \mathrm{p}=.000)$} \\
\hline \multirow{14}{*}{$\begin{array}{l}\text { Determinants } \\
\text { to } \\
\text { purchasing }\end{array}$} & Product Factor & & 2.176 & 21.765 & .662 \\
\hline & Purchase considering product quality and function & .789 & & & \\
\hline & Purchase considering the price of the product & .708 & & & \\
\hline & Purchase considering the ease of use of the product & .737 & & & \\
\hline & Brand Factor & & 2.067 & 20.671 & 694 \\
\hline & Purchase considering the brand image of the product & 612 & & & \\
\hline & Purchase considering the manufacturer of the product & .800 & & & \\
\hline & Purchase considering the reputation and trust of the product & 643 & & & \\
\hline & Purchase considering the country of origin of the product & 614 & & & \\
\hline & Evaluation Factor & & 1.939 & 19.395 & .715 \\
\hline & Considering product experience or reviews & .749 & & & \\
\hline & Considering the surrounding image of the product & .716 & & & \\
\hline & Considering the evaluation of the people around me & .738 & & & \\
\hline & $\mathrm{KMO}=.801$, Bartlett $=565.203(\mathrm{df}=136, \mathrm{p}=.000)$ & & & & \\
\hline
\end{tabular}

\section{3. 연구가설 검증}

\subsection{1 세대 간 소비성향 차이 검증}

베이비 부머 세대와 밀레니얼 세대 간의 소비성향에 지각된 차이는 독립표본 t-test 를 이용하여 검증되었다. 분석 결과, Table: 3 에서와 같이, 베이비 부머 세대와 밀레니얼 세대에 따른 자원절약 성향 $(\mathrm{t}=4.110$, $\mathrm{p}<.01)$ 과 충동구매성향 $(\mathrm{t}=-3.510, \mathrm{p}<.01)$ 이 통계적으로 유의한 차이를
보이는 것으로 나타났다. 자원절약성향은 베이비 부머 세대(M=5.44)가 밀레니얼 세대(M=4.76) 보다 높게 나타났으며, 충동구매성향은 이와 반대로 베이비 부머 세대( $M=2.99)$ 가 밀레니얼 세대( $M=3.67)$ 보다 낮게 나타났다.

그러나 타인의식성향과 계획구매 성향은 세대 간의 차이가 통계적으로 유의하지 않았다. 따라서 $\mathrm{H} 1$ 은 부분채택 되었다. 
Table 3: Independent Sample t-test Results for Testing Difference in Consumption Propensity between Generations

\begin{tabular}{|c|c|c|c|c|c|c|c|}
\hline \multirow{2}{*}{$\begin{array}{c}\text { Consumption } \\
\text { Propensity }\end{array}$} & \multicolumn{2}{|c|}{ Mean } & \multicolumn{2}{|c|}{ S.D. } & \multirow[b]{2}{*}{ t-value } & \multirow[b]{2}{*}{ p-value } & \multirow[b]{2}{*}{ Results } \\
\hline & $\begin{array}{c}\text { Baby Boomers } \\
(\mathrm{n}=115)\end{array}$ & $\begin{array}{c}\text { Millennials } \\
(\mathrm{n}=104)\end{array}$ & Baby Boomers & Millennials & & & \\
\hline Resource saving purchase & 5.44 & 4.76 & 1.194 & 1.240 & 4.110 & $.000^{* * * *}$ & Supported \\
\hline $\begin{array}{l}\text { Awareness propensity for } \\
\text { others }\end{array}$ & 3.92 & 4.11 & 1.443 & 1.425 & -.997 & .320 & Not supported \\
\hline Planned purchase propensity & 4.97 & 4.70 & 1.271 & 1.299 & 1.524 & .129 & Not supported \\
\hline Impulse buying propensity & 2.99 & 3.67 & 1.395 & 1.487 & -3.510 & $.001^{* * * *}$ & Supported \\
\hline
\end{tabular}

${ }^{*} \mathrm{p}<.10,{ }^{* *} \mathrm{p}<.05,{ }^{* * *} \mathrm{p}<.01$

\subsection{2 세대 간 구매결정요인 차이 검증}

베이비 부머 세대와 밀레니얼 세대 간의 구매결정요인에 지각된 차이가 있는지 검증하고자 독립표본 t-test 를 실시하였다. 분석 결과, Table: 4 에서와 같이, 베이비 부머 세대와 밀레니얼 세대에 따른 '평가요인(t=-3.493, $\mathrm{p}<.01)^{\prime}$ 이 통계적으로 유의한 차이를 보이는 것으로
나타났다. 평가요인은 베이비 부머 세대(M=4.68)가 밀레니얼 세대(M=523)보다 낮은 것으로 나타났다.

그러나 제품요인과 브랜드 요인은 세대 간의 차이가 통계적으로 유의하지 않았다. 따라서 $\mathrm{H} 2$ 는 부분채택 되었다.

Table 4: Independent Sample t-Test Results for Testing Difference in Determinants of Purchase between Generations

\begin{tabular}{|c|c|c|c|c|c|c|c|}
\hline \multirow{2}{*}{$\begin{array}{c}\text { Consumption } \\
\text { Propensity }\end{array}$} & \multicolumn{2}{|c|}{ Mean } & \multicolumn{2}{|c|}{ S.D. } & \multirow[b]{2}{*}{ t-value } & \multirow[b]{2}{*}{ p-value } & \multirow[b]{2}{*}{ Results } \\
\hline & $\begin{array}{c}\text { Baby Boomers } \\
(\mathbf{n}=115)\end{array}$ & $\begin{array}{l}\text { Millennials } \\
(\mathrm{n}=104)\end{array}$ & Baby Boomers & Millennials & & & \\
\hline Product Factor & 5.86 & 5.74 & .876 & .856 & 1.074 & .284 & Not supported \\
\hline Brand Factor & 4.95 & 4.66 & 1.088 & 1.210 & 1.845 & .066 & Not supported \\
\hline Evaluation Factor & 4.68 & 5.23 & 1.257 & 1.064 & -3493 & $.001^{* * *}$ & Supported \\
\hline
\end{tabular}

${ }^{*} \mathrm{p}<.10,{ }^{* *} \mathrm{p}<.05,{ }^{* * *} \mathrm{p}<.01$

\subsection{3. 성별에 따른 소비성향 차이 검증}

베이비 부머 세대의 성별에 따른 소비성향에 지각된 차이가 있는지 검증하고자 독립표본 t-test 를 실시하였다. 분석 결과, Table: 5 에서와 같이, 베이비 부머 세대의 남성과 여성에 따른 소비성향에는 '계획구매성향 $(\mathrm{t}=-2.605, \mathrm{p}<.01)$ '이 통계적으로 유의한 차이를 보이며 남성 $(\mathrm{M}=4.55)$ 이 여성 $(\mathrm{M}=5.18)$ 보다 낮은 것으로 나타 났다. 자원절약성향, 타인의식성향, 충동구매성향은 베이비 부머 세대의 남성과 여성 간의 차이는 통계적으로 유의하지 않는 것으로 나타났다. 한편, 밀레니얼 세대의 남성과 여성에 따른 소비성향에는 '자원절약성향 $\mathrm{t}=2308$, $\mathrm{p}<.05)$ '과 '타인의식성향 $(\mathrm{t}=2.586, \mathrm{p}<.05)$ '이 통계적으로 유의한 차이를 보이는 것으로 나타났다. 자원절약성향은 밀레니얼 세대의 남성 $(\mathrm{M}=5.00)$ 이 여성 $(\mathrm{M}=4.44)$ 보다 높은 것으로 나타났고, 타인의식성향도 밀레니얼 세대의 남성 $(M=4.42)$ 이 여성 $(M=3.70)$ 보다 높은 것으로 나타났다.
그러나 계획구매성향과 충동구매성향은 밀레니얼 세대의 남성과 여성 간의 차이는 통계적으로 유의하지 않는 것으로 나타났다. 따라서 $\mathrm{H} 3$ 은 부분 채택되었다.

\subsection{4. 성별에 따른 구매결정요인 차이 검증}

베이비 부머 세대의 성별에 따른 구매결정요인에 지각된 차이가 있는지 검증하고자 독립표본 t-test 가 실시되었다. 분석 결과, Table: 6 에서와 같이, 베이비 부머 세대의 남성과 여성에 따른 구매결정 요인에는 제품 요인, 브랜드 요인, 평가 요인의 세 개 요인에서 통계적으로 유의한 차이가 없는 것으로 나타났다. 한편, 밀레니얼 세대의 남성과 여성에 따른 구매결정요인에는 '제품요인( $\mathrm{t}=3.152$, $\mathrm{p}<.01)^{\prime}$ 이 통계적으로 유의한 차이를 보이는 것으로 나타났다.

제품요인은 밀레니얼 세대의 남성 $(\mathrm{M}=5.96)$ 이 여성 $(\mathrm{M}=5.45)$ 보다 높았다. 나머지 브랜드요인과 평가요인은 성별간의 차이가 통계적으로 유의하지 않았다. 따라서 $\mathrm{H} 4$ 는 부분채택 되었다. 
Table 5: Independent Sample T-test Results for Testing Differences in Consumption Propensity between Gender

\begin{tabular}{|c|c|c|c|c|c|c|c|c|}
\hline \multirow{2}{*}{$\begin{array}{l}\text { Consumption } \\
\text { Propensity }\end{array}$} & \multirow{2}{*}{ Generation } & \multicolumn{2}{|c|}{ Mean } & \multicolumn{2}{|c|}{ S.D. } & \multirow{2}{*}{ t-value } & \multirow{2}{*}{ p-value } & \multirow{2}{*}{ Results } \\
\hline & & Male & Female & Male & Female & & & \\
\hline \multirow{2}{*}{$\begin{array}{l}\text { Resource saving } \\
\text { purchase }\end{array}$} & B & 5.17 & 5.57 & 1.351 & 1.091 & -1.697 & .092 & Not supported \\
\hline & M & 5.00 & 4.44 & 1.224 & 1.204 & 2.308 & $.023^{*}$ & Supported \\
\hline \multirow{2}{*}{$\begin{array}{l}\text { Awareness } \\
\text { propensity } \\
\text { for others }\end{array}$} & B & 3.79 & 3.98 & 1.381 & 1.478 & -.674 & .502 & Not supported \\
\hline & M & 4.42 & 3.70 & 1.416 & 1.347 & 2.586 & $.011^{*}$ & Supported \\
\hline \multirow{2}{*}{$\begin{array}{l}\text { Planned purchase } \\
\text { propensity }\end{array}$} & B & 4.55 & 5.18 & 1.334 & 1.189 & -2.605 & $.010^{*}$ & Supported \\
\hline & M & 4.78 & 4.60 & 1.381 & 1.188 & .700 & . 486 & Not supported \\
\hline \multirow{2}{*}{$\begin{array}{l}\text { Impulse buying } \\
\text { propensity }\end{array}$} & B & 3.05 & 2.96 & 1.564 & 1.310 & .338 & .736 & Not supported \\
\hline & M & 3.54 & 3.87 & 1.573 & 1.358 & -1.113 & .269 & Not supported \\
\hline
\end{tabular}

${ }^{*} \mathrm{p}<.10,{ }^{* *} \mathrm{p}<.05,{ }^{* * * *} \mathrm{p}<.01$

Note: B(Baby Boomers: Male $(n=39)$ / Female $(n=76)), M($ Millennials: Male(n=60) / Female $(n=44))$

Table 6: Independent SampleTt-test Results for Testing Differences in Determinants to Purchasing between Generations

\begin{tabular}{|c|c|c|c|c|c|c|c|c|}
\hline \multirow{2}{*}{$\begin{array}{l}\text { Consumption } \\
\text { Propensity }\end{array}$} & \multirow{2}{*}{ Generation } & \multicolumn{2}{|c|}{ Mean } & \multicolumn{2}{|c|}{ S.D. } & \multirow{2}{*}{ t-value } & \multirow{2}{*}{ p-value } & \multirow{2}{*}{ Results } \\
\hline & & Male & Female & Male & Female & & & \\
\hline \multirow{2}{*}{ Product Factor } & B & 5.68 & 5.96 & .830 & .888 & -1.641 & .103 & Not supported \\
\hline & M & 5.96 & 5.45 & .736 & .926 & 3.152 & $.002 * *$ & Supported \\
\hline \multirow{2}{*}{ Brand Factor } & B & 4.99 & 4.92 & 1.146 & 1.064 & .306 & .760 & Not supported \\
\hline & M & 4.80 & 4.48 & 1.219 & 1.188 & 1.307 & .194 & Not supported \\
\hline \multirow{2}{*}{ Evaluation Factor } & B & 4.60 & 4.72 & 1.216 & 1.285 & -.470 & .639 & Not supported \\
\hline & M & 5.36 & 5.07 & 1.123 & .966 & 1.392 & .167 & Not supported \\
\hline
\end{tabular}

$* \mathrm{p}<.10, * * \mathrm{p}<.05, * * * \mathrm{p}<.01$

Note: B(Baby Boomers: Male(n=39) / Female(n=76)), M(Millennials: Male(n=60) / Female(n=44))

\subsection{5. 소비성향과 구매결정요인 간의 관계}

베이비 부머와 밀레니얼 세대 각각의 소비성향과 구매결정요인 간에 어느 정도 밀접한 관련이 있는지를 판단하기 위해서 정준상관 분석(canonical correlation analysis)이 실시되었다.

정준상관분석에서 각 변수의 중요성은 정준교차적재치(canonical cross loading)를 이용하여 판단된다. 정준교차적재치는 변수군으로 부터 어느 한 변수와 다른 변수군으로부터 유도된 정준변량과의 상관관계를 나타내는 것으로 한 변수와 다른 집단의 변수들을 대표하는 정준변량과의 관계 정도를 나타낸다(Lee \& Yoon, 2007).

적재치의 부호는 관계의 방향을 나타내고 적재치의 크기는 관계의 정도를 나타내는데, 본 연구에서는 본 연구에서는 적재량의 크기가 절대값 3 이상을 기준으로 정준상관 관계가 파악되었다. 분석 결과, 전체 3 개의 정준상관함수가 도출되었으며, 가능성 비율(likelihood ratio)을 의미하는 Wilk's Lamda 값을 살펴본 결과, 베이비 부머 세대 함수 $3(r=153$, $\lambda=.976, p>05)$ 과 밀레니얼 세대 함수 $3(r=186, \lambda=.965, p>05)$ 을 제외한 베이비 부머 세대 함수 $1(r=674, \lambda=449, p<.01)$, 밀레니얼 세대 함수 $1(r=.616, \lambda=462, p<.01)$ 과 베이비 부머 세대 함수 $2(r=395, \lambda=.824$, $p<.01)$, 밀레니얼 세대 함수 $2(r=.479, \lambda=.744, p<.01)$ 에서 유의미한 것으로 판단되었다. 따라서 $\mathrm{H} 5$ 와 $\mathrm{H6}$ 는 채택되었다. 정준상관분석 결과, 함수 2 보다 함수 1 이 좀 더 통계적으로 유의미한 설명력을 가지는 함수로 나타났다. 따라서 본 연구에서는 함수 1 을 중심으로 정준상관분석 결과를 살펴보았다 (Table: 7, Figure: 2 참조).

정준변량군들 간의 상대적인 설명력을 나타내는 함수별 정준 중복지수(Redundancy Coefficient Index)는 구매결정요인요인에 의하여 설명되는 베이비 부머 세대의 소비성향 정준상관함수 1 은 177 로 나타났고, 밀레니얼 세대의 소비성향 정준상관함수 1 은 152 로 나타났다. 또한 소비성향에 의해 설명되는 베이비 부머 세대의 
구매결정요인 정준상관함수 1 은 .169 로 나타났고, 밀레니얼 세대의 구매결정요인 정준상관함수 1 은 117 로 나타났다.

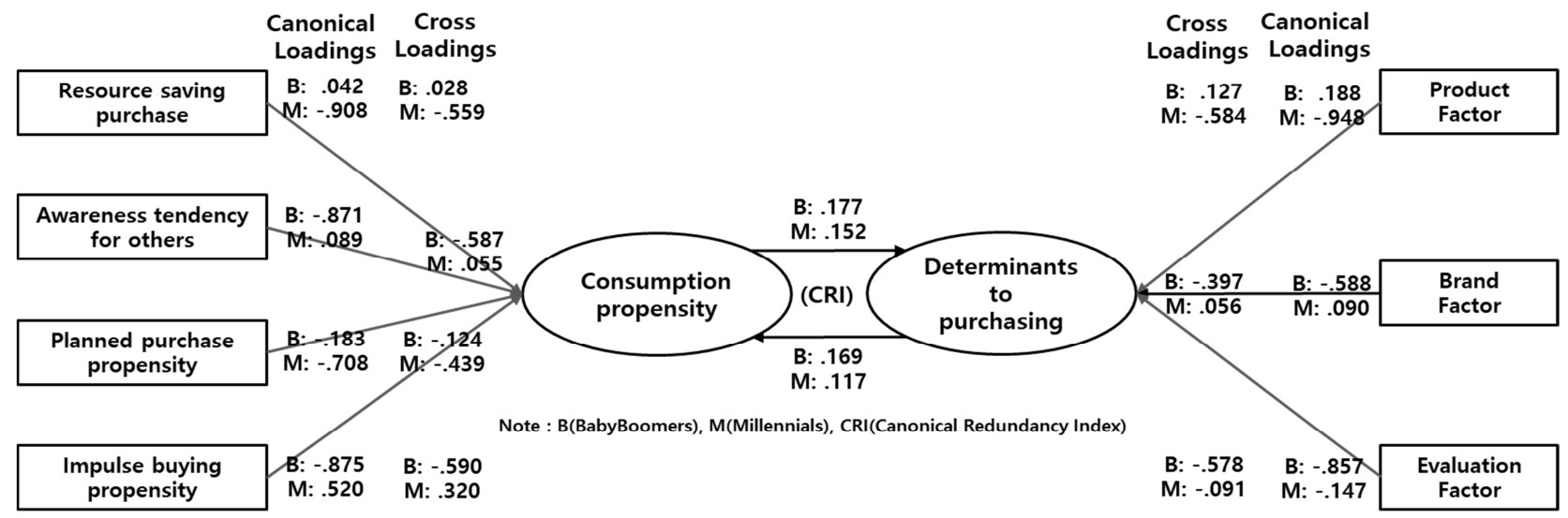

Figure 2: Structural Coefficients of Canonical Correlation

Table 7: Results of Canonical Correlation

\begin{tabular}{|c|c|c|c|c|c|c|c|c|c|c|c|c|c|c|c|c|c|c|c|}
\hline \multirow{3}{*}{\multicolumn{2}{|c|}{ Factors }} & \multicolumn{6}{|c|}{$\begin{array}{l}\text { Standardized canonical } \\
\text { correlation coefficients }\end{array}$} & \multicolumn{6}{|c|}{ Canonical loadings } & \multicolumn{6}{|c|}{ Cross loadings } \\
\hline & & \multicolumn{2}{|r|}{1} & \multicolumn{2}{|c|}{2} & \multicolumn{2}{|r|}{3} & \multicolumn{2}{|c|}{1} & \multicolumn{2}{|c|}{2} & \multicolumn{2}{|c|}{3} & \multicolumn{2}{|c|}{1} & \multicolumn{2}{|c|}{2} & \multicolumn{2}{|c|}{3} \\
\hline & & B & M & B & $\mathbf{M}$ & B & $\mathbf{M}$ & B & $\mathbf{M}$ & B & $\mathbf{M}$ & B & $\mathbf{M}$ & B & $\mathbf{M}$ & $\mathbf{B}$ & $\mathbf{M}$ & B & $\mathbf{M}$ \\
\hline \multirow{4}{*}{$\mathrm{CP}$} & ASP & -.088 & -.697 & .308 & .302 & -.777 & -.075 & .042 & -.908 & .664 & .239 & -.700 & -.211 & .028 & -.559 & .262 & .014 & -.107 & .016 \\
\hline & $\mathrm{APO}$ & -.496 & -.024 & -.337 & .781 & -.683 & .723 & -.871 & .089 & -.094 & .920 & -.353 & .316 & -.587 & .055 & -.037 & .441 & -.054 & .059 \\
\hline & PPP & -.100 & -.424 & .843 & .038 & .573 & -.557 & -.183 & -.708 & .941 & .089 & .038 & -.338 & -.124 & -.439 & .371 & .043 & .006 & -.063 \\
\hline & IBP & -.633 & .133 & .174 & .445 & .523 & -1.012 & -.875 & .520 & -.168 & .605 & .369 & -.583 & -.590 & .320 & -.066 & .290 & .057 & -.108 \\
\hline \multicolumn{2}{|c|}{$\begin{array}{c}\text { Redundancy } \\
\text { Coefficient } \\
\text { Index }\end{array}$} & .177 & .152 & .053 & .070 & .004 & .005 & & & & & & & & & & & & \\
\hline \multirow{3}{*}{ DP } & $\mathrm{PF}$ & .536 & -1.020 & .910 & -.082 & .910 & -.251 & .188 & -.948 & .980 & .239 & -.059 & -.211 & .127 & -.584 & .387 & .114 & -.009 & -.039 \\
\hline & $\mathrm{BF}$ & -.185 & .337 & .110 & .385 & .110 & -1.079 & -.588 & .090 & .437 & .778 & .680 & -.621 & -.397 & .056 & .173 & .373 & .104 & -.116 \\
\hline & $\mathrm{EF}$ & -.922 & -.020 & .124 & .762 & .124 & .951 & -.857 & -.147 & .486 & .945 & -.171 & .291 & -.578 & -.091 & .192 & .453 & -.026 & .054 \\
\hline \multicolumn{2}{|c|}{$\begin{array}{l}\text { Redundancy } \\
\text { Coefficient } \\
\text { Index }\end{array}$} & .169 & .117 & .072 & .119 & .004 & .006 & & & & & & & & & & & & \\
\hline \multirow{2}{*}{\multicolumn{2}{|c|}{ Function }} & \multicolumn{6}{|c|}{ Canonical function 1} & \multicolumn{6}{|c|}{ Canonical function 2} & \multicolumn{6}{|c|}{ Canonical function 3} \\
\hline & & \multicolumn{3}{|c|}{ Baby Boomers } & \multicolumn{3}{|c|}{ Millennials } & \multicolumn{3}{|c|}{ Baby Boomers } & \multicolumn{3}{|c|}{ Millennials } & \multicolumn{3}{|c|}{ Baby Boomers } & \multicolumn{3}{|c|}{ Millennials } \\
\hline \multicolumn{2}{|c|}{$\begin{array}{c}\text { Canonical } \\
\text { Correlations }\end{array}$} & \multicolumn{3}{|c|}{.674} & & .616 & & & .395 & & & .479 & & & .153 & & & .186 & \\
\hline Eig & ivalue & & .834 & & & .611 & & & .185 & & & .298 & & & .024 & & & .036 & \\
\hline Wilk & Lamda & & .449 & & & .462 & & & .824 & & & .744 & & & .976 & & & .965 & \\
\hline & -SQ & & 87.982 & & & 76.547 & & & 21.251 & & & 29.339 & & & 2.620 & & & 3.489 & \\
\hline & If & & 12.000 & & & 12.000 & & & 6.000 & & & 6.000 & & & 2.000 & & & 2.000 & \\
\hline & ig. & & $.000^{* * *}$ & & & $.000^{* * *}$ & & & $.002 * * *$ & & & $.000^{* * *}$ & & & .270 & & & .175 & \\
\hline
\end{tabular}

${ }^{*} \mathrm{p}<0.10,{ }^{* *} \mathrm{p}<0.05,{ }^{* * *} \mathrm{p}<0.01$

Note: B(Baby Boomers), M(Millennials), CP(Consumption Propensity), DP(Determinants of purchase), ASP(Resource saving purchase),

ATO(Awareness purchase for others), PPP(Planned purchase propensity), IBP(Impulse buying propensity), PF(Product Factor),

$\mathrm{BF}$ (Brand Factor), EF(Evaluation Factor) 
정준교차부하량(Cross Loading)을 살펴보면 정준함수 1 에서 베이비 부머 세대의 소비성향은 .3미만인 자원절약성향(.028)과 계획구매 성향(.124)을 제외하고 충동구매성향(-590), 타인의식성향(-587) 순으로 나타났으며, 밀레니얼 세대의 소비성향은 3미만인 타인의식성향.(055)을 제외하고 자원절약성향(-559), 계획구매성향 $\quad(-439)$, 충동구매성향(320) 순으로 나타나 베이비 부머 세대와는 상관계수의 차이를 보이고 있다. 베이비 부머 세대의 구매결정요인 은 3 미만인 제품요인(127)를 제외하고 평가요인(-578), 브랜드요인(-397) 순으로 나타났다.

밀레니얼 세대의 구매결정요인은 3 미만인 브랜드요인(.056), 평가요인(-091)을 제외하고 제품요인(-584)이 가장 큰 수치를 나타내고 있으며 구매결정요인 또한 베이비 부머 세대와는 상관계수의 차이를 보이고 있다. 베이비 부머 세대에서는 충동구매 성향과 평가요인이 가장 큰 연관성을 갖는 것을 볼 수 있으며 밀레니얼 세대에서는 자원절약성향과 제품요인이 가장 큰 연관성을 갖는 것을 볼 수 있다. 따라서 $\mathrm{H} 7$ 은 채택되었다.

\section{5. 결론}

본 연구는 홉스테드의 문화차원 모형이론을 바탕으로 베이비 부머와 밀레니얼 세대 각각의 소비성향과 구매결정요인을 비교 연구하였다. 이를 통해 세대 간의 차이를 확인함으로써 보다 세대 간의 올바른 이해와 구체적이고 정확한 프랜차이즈 마케팅 전략을 수립하는데 필요한 실무적 및 이론적 시사점을 제시하고자 하였다.

이론적 측면에서 홉스테드의 문화차원 모형이론은 대부분 지역이나 국가의 문화 차이를 기반으로 연구가 이루어져 왔다. 본 연구에서는 세대 간의 문화 차이로 접근하였으며 실증연구를 통해 명확하게 그 차이를 확인하였다. 또한, 베이비 부머와 밀레니얼 세대의 연구는 대게 각 세대의 개별 연구로 이루어졌으나 베이비 부머와 밀레니얼 세대를 직접 비교 연구하여 그 차이를 확인함으로 세대별로 갖는 가치가 다름을 확인하였다. 이러한 연구 결과는 표적고객에 대한 향후 다양한 연구 분야에서 세대별 연구의 필요성을 제시하였다는 것에 그 의미가 크다고 할 수 있다.

실무적 측면으로 시장에서 인구통계상 가장 핵심적인 비중을 차지하는 베이비 부머와 밀레니얼 세대의 프랜차이즈 산업분야의 전략적 마케팅 시사점은 다음과 같다.

첫째, 본 연구는 선행연구를 바탕으로 소비성향의 하위 영역으로 자원절약성향, 타인의식성향, 계획구매성향, 충동구매성향으로 구분하였고, 구매결정요인의 하위 영역으로는 제품 요인, 브랜드 요인, 평가 요인으로 구분하였다. 베이비 부머와 밀레니얼 세대에서
소비성향의 차이는 자원절약성향과 충동구매성향에서 유의한 차이 가 발생하였다. 자원절약성향은 베이비 부머 세대가 더 높은 것으로 나타났다. 이는 우리나라 베이비 부머의 은퇴에 대해 살펴보면, 최초 베이비 부머 세대가 만 55 세에 이른 2010 년부터 베이비 부머의 은퇴가 시작되었으며 2020 년까지 총 150 만 명 정도의 베이비 부머가 은퇴할 것으로 예상된다(Jung et al, 2011). 베이비 부머 세대는 자신의 소득확보의 어려움은 물론, 부동산 시장 침체로 이어져 전반적으로 경제의 근간이 흔들릴 수밖에 없는 상황에 처해 있다는 것이다Baek, 2011). 따라서 이들은 값싼 물건이라도 소중하며 아끼고, 물건을 살 때는 언제나 자신의 형편과 처지에 적절한 가를 생각해 보며, 쓰던 물건을 오래 사용하려는 소비성향을 갖게 된다. 반대로 밀레니얼 세대는 충동구매성향이 더 높은데, '미래 가치보다 오늘의 행복에 더 많은 것을 집중한다(긍정 $43.4 \%$, 보통 $34.8 \%$, 부정 $22.0 \%$ )의 조사 결과와 같이 편리한 물품을 자주 구입하며 새롭게 눈에 띄는 것이 있으면 즉시 사용하는 지금의 행복에 더 많은 투자(Lee, 2017)를 하는 충동구매성향이 더 높은 것으로 나타났다.

따라서 소비성향은 베이비 부머 세대를 목표로 하는 프랜차이즈 분야는 제품과 서비스를 구성하는데 있어 높은 가성비와 경제성을 중심으로 해야 한다. 베이비 부머 세대가 주로 이용하는 시장이나 마트의 사례 중 최근 이마트의 PB 제품으로 시작된 자체 브랜드 '노브랜드(NoBrand)'와 같이 브랜드의 이미지보다 실리적인 가성비와 경제성을 최우선 마케팅 전략으로 2015 년 매출 230 억 원에서 2017 년 2,900 억 원으로 급성장하며 매년 꾸준한 성장(Lee, Cho \& Choi, 2019)을 보이고 있다.

이러한 마트, 편의점 등의 도·소매 중심의 프랜차이즈는 브랜드의 이미지 광고나 투자보다 실리를 중심으로 한 마케팅 전략이 더 중요하다는 사실을 잘 보여주고 있다. 따라서 경품, 정기적인 가격할인, 쿠폰, 특매, 누적 구매에 따라 일정한 혜택을 주는 연속성(Continuity) 전략을 각 프랜차이즈 가맹점에 적용하는 것이 도.소매 중심의 프랜차이즈 분야에서 필요한 마케팅 전략으로 판단된다.

밀레니얼 세대는 소비성향에서 충동구매성향으로 '당장의 욕구를 얼마나 빨리 충족시켜 주는가?와 구매결정요인에서 평가요인이 더 높은 것으로 나타났다. 이들 세대의 가장 큰 특징은 디지털 네이티브(Digital Natives), 즉 최초의 디지털 원주민 세대로 인터넷이 '늘' 연결된 환경에서 나고 자라, 소셜 네트워킹 서비스 (SNS)를 내 몸의 일부처럼 여기며 살아오고 소셜 네트워킹 서비스 내에서의 평가를 매우 중요하게 여기고 있다(Kang, 2004). 국내 음식 배달앱 시장은 O2O(Online to Offline)를 기초로 발전한 서비스로 단순 광고 플랫폼에서 발전하여 음식을 주문 후 후기를 통한 서비스로 평판을 제공하고 있다. 밀레니얼 세대를 중심으로 성장하고 있는 배달앱 시장은 다운로드 건수는 4,000 만 건을 넘어섰으며 2015 년 배달앱 시장은 전체 배달 시장의 
$10 \%$ 의 점유율로, 연간 1 조 원대의 시장으로 성장하였다KKim \& Lee, 2017; Lee et al, 2018).

밀레니얼 세대의 '얼마나 빨리 욕구를 충족시켜 주는가?', '주변의 평판은 어떠한가'의 소비성향과 구매결정 요인을 보여주는 좋은 예로 볼 수 있다. 따라서 배달 중심의 외식 프랜차이즈, 밀레니얼 세대 목표의 브랜드(의류, 액세서리, 신발 등)의 프랜차이즈는 브랜드나 상품에 대하여 대중 매체를 통한 홍보보다 쇼설 네트워킹 서비스를 중심으로 전개하는 것이 더 적절할 것으로 판단된다. 내용적 측면에서 전통적인 정보 전달이나 브랜드 이미지 노출보다 각 프랜차이즈 성격과 특성에 맞게 좋은 이미지를 만들 수 있는 이벤트 판촉, 직접적이고 적극적 참여 유도의 소비자 콘테스트, 사용자 경험, 상품이나 서비스의 우수성을 알릴 수 있는 베스트 후기 등의 판매촉진 적용이 더 필요한 마케팅 전략으로 판단된다.

둘째, 베이비 부머 세대와 밀레니얼 세대에 성별 차이에서 소비성향과 구매결정요인은 베이비 부머 세대에서 계획구매성향 에서 여성이 더 높은 것으로 나타났으나 구매결정요인에서는 유의한 차이는 발생하지 않았다. 한국 여성 정책 연구원의 조사에서 베이비 부머 세대의 성별 경제활동 참가율은 남성 $914 \%$, 여성 $62.9 \%$, 고용률 남성 $88.7 \%$, 여성 618\%로 조사되었다KKm, 2010). 이는 대부분의 베이비 부머 세대의 여성은 가사를 담당하거나 전업 주부인 것을 보여 주는 것으로, 가정 소득의 주체는 남성이나 실제 가정에서 발생된 소득을 사용하는 것은 전업 주부인 여성이다. 따라서 가계에서 발생한 소득에 대해서 여성이 지출에 더 민감하게 반응하고 불필요한 낭비를 줄이기 위해 계획구매성향이 더 높은 것으로 판단된다.

베이비 부머 세대의 여성은 물건을 살 때는 미리 계획을 세워 여러 상점을 살펴보고 비교한 후 구입하며 구입 목록대로 구입하는 등의 성향을 가지고 있다. 이러한 소비성향을 바탕으로 프랜차이즈 내의 할인 정보를 사전에 충분히 알리고 다양하고 정확 한 상품 정보를 수시로 고시하는 마케팅 전략이 필요하다.

밀레니얼 세대에서는 소비성향 중 자원절약성향, 타인의식성향과 구매결정 요인 중 제품요인이 모두 남성이 더 높은 것으로 나타났다. 우리나라의 밀레니얼 세대의 여성은 결혼을 미루거나 포기하는 사람들이 늘어나고 극심한 청년실업으로 취업대신 취집(취업+ 시집)을 선택하려는 젊은 여성이 높아지고 있다(leong, 2009). 신혼 부부의 결혼비용은 평균 2 억 6 천만 원 중 신랑이 신부의 두 배 정도의 비용이 든다(Duowed, 2017). 또한 소비자 조사 전문기관인 컨슈머 인사이트의 조사결과에서 온라인 쇼핑 시 주 이용 디바이스 는 모바일 $57 \%, \mathrm{PC}$ $32 \%$ 로 나왔으며, 주 이용 연령대는 20-30 대에서 남성은 $58.5 \%$, 여성은 $76 \%$ 로 압도적으로 여성이 높았다(leong, 2019). 이러한 사회적 상황 속에서 밀레니얼 세대의 남성은 취업, 결혼과 같은 미래에 대한 준비로 여성에 비해 상대적으로 소비를 하는데 있어 '알뜰함을 강조하는 자원절약성향이 더 높은 것으로 판단된다. 한편, 타인의식성향 또한,
남성이 더 높은 것으로 밀레니얼 세대의 남성은 결혼적령기와 취업 세대로서 자신의 대한 사회적 평가에 대해 민감하게 반응하는 것으로 판단된다. 가격비교 전문 사이트인 마이마진(mwwmymargin.com)은 인터넷 쇼핑 시 남자가 여자보다 더 민감하게 반응한다는 조사결과를 발표하였다(Lim, 2004).

밀레니얼 세대의 남성은 '가성비'와 '경제성' 그리고 제품의 실리적인 성능을 고려하고 그렇게 구입한 상품이나 서비스가 타인으로부터 '어떠한 평가를 받는가?'에 높은 관심을 가지고 있는 것으로 판단된다. 밀레니얼 세대의 남성을 목표로 프랜차이즈 마케팅 전략을 수립 시 상품이나 서비스에 대한 유사 제품과 비교, 소비자 만족 평판 등의 서비스를 사전 충분히 제시하여 가성비와 경제성을 증명하기 위한 노력이 필요하다. 가성비를 높이기 위해 저가 브랜드라는 상품이나 이미지를 갖지 않도록 주의를 기울여야 한다. '합리적인 가격대에 비해 품질이 높고, 제품 디자인은 다른 브랜드에 비해 단순한 것'의 제품 철학을 가진 패션 브랜드인 유니클로(UNIQLO)는 밀레니얼 세대에 많은 인기를 가지고 있어(Rhee \& Choi, 2012), 이러한 대표적인 성공사례로 볼 수 있다.

셋째, 소비성향의 하위요인인 자원절약성향 타인의식성향, 계획구매성향, 충동구매성향과 구매결정요인인 제품요인, 브랜드 요인, 평가요인을 정준상관분석하여 베이비 부머 세대와 밀레니얼 세대 모두 하위요인 변인 군 간에 서로가 영향력을 가지는 것으로 밝혀졌다. 그 중 베이비 부머 세대의 소비성향 중 충동구매성향과 평가요인이 가장 밀접한 관계가 있으며 밀레니얼 세대에서는 자원절약성향과 제품요인이 가장 밀접한 유의한 관계로 나타났다. 이는 베이비 부머 세대는 스스로 제품을 충동적으로 소비하는데 있어 타인의 평가에 관심을 귀 기울이고, 밀레니얼 세대는 경제성과 가성비를 고려하여 소비하는데 있어 제품의 기능성을 중요시한다는 사실을 알 수 있다.

따라서 프랜차이즈 마케팅 전략을 수립하는데 있어 베이비 부머 세대에서 충동적인 소비가 이루어지는 환경 (이벤트, 할인, 관광상품 등)에서는 주변인의 평가를 고려한 전략수립이 필요하다. 프랜차이즈 가맹점 내 서비스 스케이프(servicescape) 향상에 관심을 가지며 특히, 종업원의 태도, 종업원과 고객의 상호작용, 서비스 능력 등의 사회적 환경에 지속적인 노력과 관심을 가져야 한다. 밀레니얼 세대의 남성은 가성비와 경제성을 고려하여 제품의 품질이나 기능, 가격 등을 중요시하기 때문에 프랜차이즈에서 제공되는 서비스나 상품이 가격보다 양질로 제공받고 있음을 인식하는 것이 중요하며 가격에 비해 질이 낮지 않게 하는 것이 더 주의를 기울여야 한다. 사례로서 독특한 분위기와 소비자 맞춤형 서비스를 제공하는 대형 샌드위치 전문점인 서브웨이(SubWay)는 중저가의 샌드위치(6,000 원 7,000 원)를 판매함으로써 고가의 음식이 부담스럽거나 편의점 음식과 같은 저가의 음식으로 허기를 채우는 대신 간단하고 풍족한 식사를 제공한다. 이는, 밀레니얼 남성 세대에 맞는 마케팅 전략 방식의 사례로 볼 수 있다. 
한편, 본 연구의 한계점은 다음과 같으며, 이에 따라 향후 연구 방향을 제시하고자 한다.

첫째, 본 연구의 대상은 현 시대를 살아가는 베이비 부머 세대와 밀레니얼 세대로 시간이 지남에 따라 그들의 사회적, 경제적 상황은 달라 질 것이다. 따라서 세대에 관한 연구는 지속적인 추적을 통한 종적 연구와 더불어 깊이 있는 횡적 연구를 진행한다면 더욱 의미 있는 연구결과를 도출할 것으로 판단된다.

둘째, 선행연구에서 주로 사용되는 소비성향과 구매결정요인의 하위요인을 바탕으로 연구가 진행되었다. 따라서 향후 연구에서는 각 시장(제조, 서비스 등)에서 필요로 하는 소비성향과 구매결정요인을 바탕으로 시장 별 연구가 진행된다면 각 시장에 더욱 적합한 세부적인 시사점을 제시할 수 있을 것으로 사료된다.

\section{References}

Baek, E. Y. (2011). Determinants of retirement preparation and the types of preparation of the baby boomers. Korean Social Security Studies, 27(2), 357-383.

Chung, E. E. (2019). A study on the influence of millennial generation on broadcasting contents production: Focusing on expert interview, Journal of the Korean Society Design Culture, 41(4), 613-654.

Choi, S. J. (2016). Study on the type of selecting channels through the on-line about restaurant information by baby boomer consumers. Journal of the Korean Gerontological Society, 36(3), 711-726.

Darden, W. R., \& Howell, R. D. (1987). Socialization effects of retail work experience on shopping orientations. Journal of theacademy of Marketing Science, 15(3), 52-63.

Duowed. (2017). Marriage Cost Status Report in 2017.

Engel, J. F., Blackwell, R. D., \& Miniard, P. W. (1986). Consumer Behavior: Instructor's Manual and Test Bank. Dryden Press.

Ha, J. K. (2019). The effects of consumption propensities on product preference and purchase decision factors in health \& beauty store. The Korean Society of Beauty and Art, 20(3), 119-132.

Hidden Grace (2018). Thesis to pass at once. Hanbit Academy.

Hofstede, G. (1980). Culture's Consequences: International Difference sin Work-related Values, Beverly Hills, California: Sage Publications.

Hofstede, G., Bram, N. D. D., Ohayv, \& Geert, S. (1990). Measuring organizational cultures: A qualitative and quantitative study across twenty cases. Administrative Science Quarterly, 35, 286-316.

Hofstede, G. (1993). Cultural constraints in management theories. Academy of Management Executive, 7(1), 81-94.

Hofstede, G., Hofstede, G. J., \& Minkov, M. (2005). Cultures and organizations: Software of the mind (Vol. 2). New York: Mcgraw-hill.

Hong, L., \& Byun, W. G. (2018). A study on the cultural contents to consider in Korean education for Chinese learners based on Hofstede`s cultural dimensions. HAN-GEUL, 79(1), 201-228.
Hong, S. C., \& Kwon, Y. J. (2019). The effects of millennials shared leadership on team efficacy and organizational wellbeing in the hotel industry: The mediating effect of team efficacy. Journal of Tourism and Leisure Research, 31(5), 229-252.

Holt, D. B. (1995). How consumers consume: A typology of consumption practices. Journal of Consumer Research, 22(1), 1-16.

Howe, N., \& Strauss, W. (1992). Generations: The history of America's future, 1584 to 2069. Harper Collins.

Hwang, S. W. (2010). Hall/Hofstede vs. McLuhan: Sorting out cultural and technological forces shaping South Korean and U.S. legislator/celebrity Web sites. Locality \& Communication, 14(1), 221-248.

Jeong, C. O. (2009). Special high school: The direction of parental education in preparation for low birth rate, aging age. Journal of Parent Education, 1(1), 9-26.

Jeong, K. S. (2019). Mobile, PC and online shopping are poised to take over. Consumer Insight, Shopping report, 2019.4.3.

Jo, Y. S., \& Cho, T. Y. (2019). A study on the characteristics of the millennium generation's space consumption. Journal of the Korean Society of Design Culture, 25(1), 413-429.

Jung, H. S., Kang, S. W., Moon, W. S., Park J., Son, M. J., Lee, C. Y., Lee, E. M., Lee, M. H., \& Park. B. S. The ripple effect and countermeasures of the retirement of the baby boom generation. Samsung Economic Research Institute, [SERI] Research Report (10), 2010.1.

Kang, L. J., \& Sin, J. B. (2006). An analysis on the determinants of consumers' decision to purchase cosmetics by their consumption propensity. Journal of Consumption Culture, 9(4), 83-103.

Kang, S. H. (2004). Digital native of the digital age. LG's Weekly Economy, 9(1), 8-14.

Kim, Y. R. (2010). A comparative study on the characteristics of men and women in the baby boom generation. Korea Women's Development Institute, 7, 1-146.

Kim, D. H. (1996). Development and application of a measurement instrument of consumption propensity. (Master's Thesis). Korea Advanced Institute of Science and Technology, Daejeon, Korea.

Kim, H. J. (2016). The affect relationship among consumption properties, selective attributes preferences and use intention in hotel customer. Journal of Tourism and Leisure Research, 28(4), 171-188.

Kim, J. J. (2019). A study on the jewelry market trend reflecting the characteristics of millennial generation: Focusing on the trend of global jewelry brands. Journal Korea Society of Visual Design Forum, 62, 115-126.

Kim, M. H, Kim A. H., \& Song, E. J. (2013). Analysis of the types of baby boomers according to dining-out consumption pattern. Journal of Foodservice Management Society of Korea, 16(5), 27-48.

Kim M. J. \& Lee, S. B. (2017). The effect of the innovativeness of delivery application users on perceived traits, satisfaction, and continuous usage intention: Using the extended technology acceptance model (ETAM), International Journal of Tourism and Hospitality Research, 31(1), 199-214.

Kim, M. J., \& Rhee, K. C. (2007). A study on the purchasing orientation of cosmetics by information search types of female 
consumers. Consumer Policy and Education Review, 3(1), 115.

Kim, S. Y., \& Lee, I. H. (2019). The effects of cosmetics consumption propensity on purchase determinants in college women, The Korean Society of Beauty and Art, 20(1), 105-117.

Korea Journal of Population Studies, KJPS. (2006). A population dictionary, Daejeon: Korean Statistical Publications.

KOSTAT, Statistics Korea (2018). Elderly Statistics in 2018.

Kupperschmidt, B. R. (2000). Multigeneration employees: Strategies for effective management. Health Care Manager, 19(1), 65-76.

Lee, Dong il, Park, Shinja. (2010). Development procedures of franchise Industries in Current state of manpower and research on its utilization. Journal of Franchise Management, 1, 43-63.

Lee, H. D., \& Lee, M. S. (2019). The values of vintage fashion for Korean millenials. Journal Korea Society of Visual Design Forum, 63(0), 55-66.

Lee. H., \& Park. C. H. (2019). An analysis of tourism experience for retired baby boomers. Journal of Tourism Sciences, 43(4), 201-227.

Lee, J. W., Kim, T. W., Lee, M. J., \& Lee, S. H. (2018). Generation Y's delivery apps choice attributes and their consequences, Journal of Franchise Management, 9(1), 27-39.

Lee, S. E. $\Gamma 2039$ Condition of Happiness: The real YOLO that the Millennial Generation says. 2018 Millennium Happiness Values $\lrcorner$. University Tomorrow 20s Lab Exploration Report, Issue Paper 2017. 12. 22, https://www.20slab.org/archives 125076.

Lee, S. G., \& Yoon, Y. S. (2007). Canonical correlations between restaurant image and perceived service quality. Journal of Foodservice Management Society of Korea, 10(4), 73-93.

Lim, H. S. (2004. May 18). Men are more sensitive to the price of Internet shopping than women. Korean Economy.

Liu Z., Cho, Y. Y., \& Hwang, S. W. (2019). A comparative study of TV public service advertisements in U.S. and China: Focusing on Hall and Hofstede's cultural theories. Journal of China Studies, 22(3), 47-72.

Lee, Y. R. Dagvadorj, A., \& Kim, H. S. (2019). A study of the influence of bakery selection attributes on customer satisfaction among millennial generation. Culinary Science \& Hospitality Research, 25(12), 1-7.

MOEL. (2017). Gwangju's baby boomer generation is 12.4 percent of the total population, the lowest among the seven special and metropolitan cities. Light Village Employment Information, 2017(5).

MOTIE. (2005). A Study on the Development of Small and Medium-Sized Distribution Industry in 2005, https://www. motie. go. kr

MOTIE. (2019). A Survey on the Status of Franchise Industry in 2018, https://www. motie. go. kr.

Park, J. H. (2010). Generational conflicts in Korea: power, ideological and cultural conflicts, Korea Journal of Population Studies, 33(3), 75-99.

Park, H. W., \& Kim, Y. S. (2004). Cosmetics purchasing according to consumption propensity of the new-aged women.
Journal of the Korean Society of Clothing and Textiles, 54(6), 59-73.

Park, S. K., Lee, K. W., \& Choi, Y. H. (2015). The study of winwin growth and problems between franchisor and franchisee. Journal of Franchise Management, 6(2), 31-49.

Park, T. J. (2013). An exploratory study for the exploring the essential meaning about work and retirement in baby boomer. Quarterly Journal of Labor Policy, 13(3), 29-57.

Rhee, D. K.., \& Choi J. (2012). Uniqlo in Korea: The joint venture of fast retailing co. and Lotte shopping co. International Business Review, 16(1), 295-325.

Ryu, J. S. (2019). Characteristics and challenges of the American millennial generation. Journal of Legislative Studies, 57(0), 217-222.

Rouse, S. M., \& Ross, A. D. (2018). The politics of millennials: political beliefs and policy preferences of America's most diverse generation. University of Michigan Press.

Shin, H. G. (2019). A structural model of baby boomers' capital dynamics and quality of life: moderated by birth cohort. Journal of Digital Convergence, 17(8), 429-437.

Shin, H. W., \& Lee, C. Y. J. (2018). A study of brand communication through the consumer trend of the millennial generation and mirrors from a dualistic perspective. Journal of the Korean Society Design Culture, 24(1), 355-364.

Smola, K. W., \& C. D. Sutton (2002). Generational differences: Revisiting generational work values for the new millennium. Journal of Organizational Behavior, 23(4), 363-382.

Song, I. U., \& Won, S. J. (2019). Effect of income on depression of Korean babyboomers: Testing moderating effect of social capital according to gender. Journal of the Korea Contents Association, 19(7), 587-597.

Sproles, G. B., \& Kendall, E. (1986). A methodology for profiling consumers' decision-making styles. Journal of Consumer Affairs, 20(2), 267-279.

Tapacross. (2017). Millennial Generation Viewed as Big Data. Seoul, Korea: Book Today.

Ye, J. E., \& Chin. H. (2009). A interview and empirical analysis on new generation workers' characteristics. Korean Journal of Resources Development, 12(2), 67-86.

Yoon, Y. J., \& Park, H. Y. (2019). Study on the influence of structural characteristics in society and economic of the baby boomer generation retirement age on the residential mobility. Journal of the Korean Housing Association, 30(4), 85-94.

Yu, M. J., \& Oh, J. K. (2018). The analysis of culture differences on festival participants by Hofstedes culture dimension model: Focused on international cultural arts tourism festival. Journal of Tourism and Leisure Research, 30(1), 21-40.

Varindra, M. R. Y. (2018). The influence of marketing mix towards purchase intention on self-service concept salad bar in millennial generation (pizza hut) (Doctoral dissertation, Sekolah Tinggi Manajemen IPMI).

Woo, C. B., \& Lee. G. O. (2008). A study on the propensity to consume of food service according to customer`s value system. International Journal of Tourism and Hospitality Research, 22(2), 159-172. 